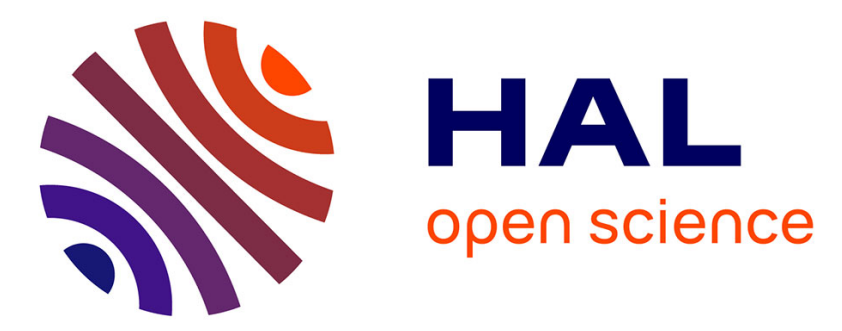

\title{
Ultrasonic shear and 'capillary viscosity study of 4-cyano-4'-n-heptylbiphenyl in the nematic and the isotropic state
}

S.D. Hunnisett, J.C.A. van Der Sluijs

\section{- To cite this version:}

S.D. Hunnisett, J.C.A. van Der Sluijs. Ultrasonic shear and 'capillary viscosity study of 4-cyano-4'n-heptylbiphenyl in the nematic and the isotropic state. Journal de Physique Lettres, 1983, 44 (2), pp.59-63. 10.1051/jphyslet:0198300440205900 • jpa-00232143

HAL Id: jpa-00232143

https://hal.science/jpa-00232143

Submitted on 1 Jan 1983

HAL is a multi-disciplinary open access archive for the deposit and dissemination of scientific research documents, whether they are published or not. The documents may come from teaching and research institutions in France or abroad, or from public or private research centers.
L'archive ouverte pluridisciplinaire HAL, est destinée au dépôt et à la diffusion de documents scientifiques de niveau recherche, publiés ou non, émanant des établissements d'enseignement et de recherche français ou étrangers, des laboratoires publics ou privés. 


\title{
LE JOURNAL DE PHYSIQUE-LETTRES
}

J. Physique - LETTRES 44 (1983) L-59 - L-63

15 JANVIER 1983, PAGE L-59

Classification

Physics Abstracts

$61.30-62.80$

\section{Ultrasonic shear and capillary viscosity study of 4-cyano-4'-n-heptylbiphenyl in the nematic and the isotropic state}

\author{
S. D. Hunnisett and J. C. A. van der Sluijs \\ School of Physical and Molecular Sciences, University College of North Wales, \\ Bangor, Gwynedd LL57 2UW, Great Britain
}

(Reçu le 27 septembre 1982, accepté le 23 novembre 1982)

\begin{abstract}
Résumé. - Nous avons mesuré les propriétés visqueuses en phase nématique et isotrope du 4-cyano4'-n-biphenyl (7-CB) par viscométrie capillaire et ultra-sonore à des fréquences comprises entre 50 et $70 \mathrm{MHz}$. En phase nématique nos résultats, comparés à ceux obtenus sous cisaillement de basse fréquence, posent d'importantes questions sur le comportement du coefficient $\alpha_{3}$ de Leslie [1, 2].

Abstract. - Using capillary viscometry and ultrasonic shear at frequencies between 50 and $70 \mathrm{MHz}$, we have measured viscous properties of 4-cyano-4'-n-biphenyl (7-CB) in the nematic and the isotropic state. The data in the nematic state, when compared with results from low frequency shear experiments, raise important questions on the behaviour of the Leslie coefficient $\alpha_{3}[1,2]$.
\end{abstract}

Viscous properties of liquid crystals may be studied with capillary viscometry, low frequency shear or ultrasound. In the present study we used conventional capillary viscometry in zero magnetic field and ultrasonic shear impedometry at frequencies between 50 and $70 \mathrm{MHz}$ [3].

Our data on the ultrasonic shear of the present compound, 4-cyano-4'-n-heptylbiphenyl or $7-\mathrm{CB}$, are new and our data on capillary viscosity are in good agreement with data obtained by other workers before [8]. Ultrasonic shear on the related compound 5-CB has been studied by Kiry et al. [6,7], whereas low frequency oscillatory shear studies have been carried out by Clark et al. [1], and by Skarp et al. [2].

The capillary viscometry was carried out for two capillary sizes, of radius $0.33 \mathrm{~mm}$ and $0.25 \mathrm{~mm}$, with mean flow speeds not less than $40 \mathrm{~mm} / \mathrm{s}$ and $25 \mathrm{~mm} / \mathrm{s}$ respectively. By this we ensure that the saturation angle of director alignment was obtained. The ultrasonic shear impedometer is of the type first proposed by Mason et al. [5] and described extensively by Martinoty et al. [3].

In figure 1 we show a sketch of the impedometer with the ultrasonic path indicated.

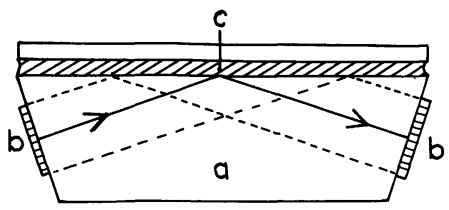

Fig. 1. - Sketch of ultrasonic impedometer and ultrasound path. a : Fused silica bloc. b : Transducers. c : Sample. 
Sample alignment parallel to the impedometer surface was obtained by unidirectional rubbing with tissues of either the clean surface, or of a thin layer of PVA (poly vinyl alcohol) which had been deposited first on the impedometer surface, both methods giving identical results. Perpendicular orientation was obtained by deposition of a layer of lecithin on the impedometer surface.

We checked the performance of the apparatus with dibutyl phtalate for which extensive literature data are available. Agreement within $1 \%$ was obtained. For some of the check experiments a layer of PVA or lecithin was deposited on the surface first. The results were identical to those obtained on a clean surface, and therefore it is safe to assume that these layers do not influence the acoustic impedance of the sample in any way other than by orientation of the liquid crystal.

Checks on frequency dependence showed no frequency dependence within the experimental error of $2 \%$. No further reference to frequency will be made.

The acoustic impedance of the sample is found from the reflection coefficient of the ultrasound against the top surface of the fused silica impedometer bloc, and hence a viscosity is found. Dependent on the orientation of the director $\mathbf{n}$ with respect to the ultrasound displacement $\mathbf{u}$ and the ultrasound wavevector $\mathbf{k}$ three different viscosity coefficients are obtained, as shown in figure 2

$$
\begin{aligned}
& \text { orientation } A: \mathbf{n} \perp \mathbf{u} \text { and } \mathbf{k}, \\
& \text { orientation } B ; \mathbf{n} / \mathbf{u} \text { and } \perp \mathbf{k}, \\
& \text { orientation } C: \mathbf{n} \perp \mathbf{u} \text { and } / / \mathbf{k} .
\end{aligned}
$$
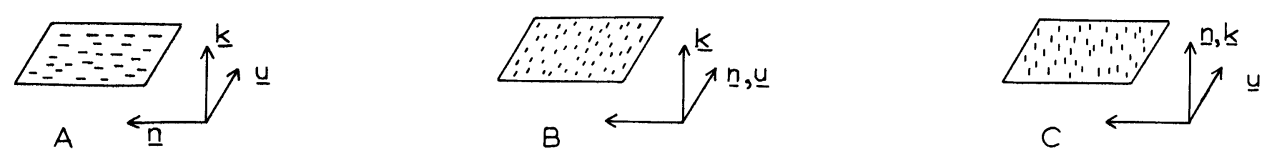

Fig. 2. - Sample orientations, A, B and $\mathbf{C}, \mathbf{n}$ is the director, $\mathbf{u}$ the ultrasound displacement and $\mathbf{k}$ the ultrasound propagation vector.

According to the Rapini equality

$$
\eta_{\mathrm{B}}=\eta_{\mathrm{C}} \equiv \eta_{\mathrm{B}, \mathrm{C}}
$$

which we found confirmed in our experiments.

For the capillary viscosity we use the symbol $\eta_{\mathrm{s}}$ and for the ultrasound viscosity in the isotropic state the symbol $\eta_{\text {us }}$.

The data for 7-CB are shown in figure 3.

For the nematic state the following relationships between the observed viscosities and the Leslie coefficients can be written down $[4,6]$.

$$
\begin{aligned}
& \eta_{\mathrm{s}}=\frac{1}{4} \alpha_{1}\left(1-\gamma_{1}^{2} / \gamma_{2}^{2}\right)+\frac{1}{2}\left(\alpha_{2}+\alpha_{4}+\alpha_{5}\right) \quad \text { (at saturation angle) } \\
& \eta_{\mathrm{A}}=\frac{1}{2} \alpha_{4} \\
& \eta_{\mathrm{B}}=\frac{1}{2}\left(\alpha_{4}+\alpha_{6}-\alpha_{3} \gamma_{2} / \gamma_{1}\right) \\
& \eta_{\mathrm{C}}=\frac{1}{2}\left(\alpha_{4}+\alpha_{5}-\alpha_{2} \gamma_{2} / \gamma_{1}\right) \\
& \gamma_{1}=\alpha_{3}-\alpha_{2} \\
& \gamma_{2}=\alpha_{3}+\alpha_{2}=\alpha_{6}-\alpha_{5} .
\end{aligned}
$$

Therefore for $\alpha_{3}=0$

$$
\eta_{\mathrm{s}}=\eta_{\mathrm{B}, \mathrm{C}}
$$




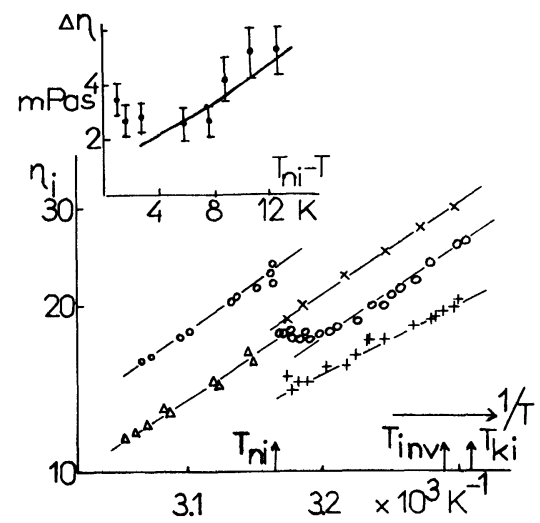

Fig. 3. - Data on 7-CB. O capillary viscometer data ; $\times$ orientation $\mathrm{A} ;+$ orientation $\mathrm{B}, \mathrm{C} ; \Delta$ ultrasound data in isotropic state. Inset $: \Delta \eta v s . T_{\mathrm{c}}-T$. Drawn lines best fit to equation (7).

For $\alpha_{3} \neq 0$, defining $\Delta \eta=\eta_{\mathrm{s}}-\eta_{\mathrm{B}, \mathrm{C}}$

$$
\Delta \eta=\alpha_{2} \alpha_{3}\left[\alpha_{1} / \gamma_{2}^{2}+1 / \gamma_{1}\right]
$$

Although the experiment accuracy on $\Delta \eta$ is only $25 \%$ it follows clearly from figure 3 that $\Delta \eta$ is everywhere significantly different from zero, the lowest value being $(2.6 \pm 0.6) \mathrm{mPaS}$.

From equation (5) we have

$$
\begin{aligned}
\alpha_{2}, \alpha_{3} & \neq 0,0 \\
\alpha_{1} & \neq-\gamma_{2}^{2} / \gamma_{1},
\end{aligned}
$$

over the whole nematic range.

The fact that $\alpha_{2} \neq 0$ is unremarkable, being in line with other nematics. However, we find that also $\alpha_{3} \neq 0$ over the whole nematic range. Our data do not allow to find a numerical value for $\alpha_{3}$ as $\alpha_{1}$ and $\alpha_{2}$ are unknown. Some idea of its magnitude can be obtained though by inserting " typical " values for $\alpha_{1}$ and $\alpha_{2}$ in equation (5). For convenience we take $\alpha_{1}=10 \mathrm{mPaS} ; \alpha_{2}=$ $-80 \mathrm{mPaS}$. At $T_{\mathrm{c}}-T=2 \mathrm{~K}$ this yields

$$
\begin{aligned}
\alpha_{3} & =-1.8 \mathrm{mPaS} \\
\gamma_{1} / \gamma_{2} & =-0.96 .
\end{aligned}
$$

This behaviour of $\alpha_{3}$ agrees with the data obtained by Skarp et al. [2], but is at variance with the behaviour which Clark et al. [1] deduce from observations of instability onset in low frequency oscillatory shear experiments. From these experiments it follows that $\alpha_{3}$ is negative for $T>31{ }^{\circ} \mathrm{C}$, in agreement with our observations. However at $T=31{ }^{\circ} \mathrm{C}$, the inversion temperature, $\alpha_{3}$ becomes 0 , whereas at even lower temperatures, continuing in the undercooled state for $T<T_{\mathrm{KN}}$, $\alpha_{3}$ is observed to be positive. We have marked the inversion temperature in our figure 3 , and it is evident, that there is no feature at all in $\Delta \eta$ at this temperature, which excludes such behaviour for $\alpha_{3}$ by equation (5).

This descrepancy raises interesting questions with respect to the interpretation of the data. Expression ( $3 a$ ) for the capillary viscosity at saturation angle assumes that $\alpha_{3}$ is negative, and is invalid otherwise. For positive $\alpha_{3}$ the alignment angle might stabilize at some different value due to subtleties not included in the simple theory used to derive $(3 a)$. Alternatively disclinations might form, invalidating $(3 a)$. 
On the other hand, the existence of an inversion temperature for $\alpha_{3}$ at $31^{\circ} \mathrm{C}$ makes it necessary that $\alpha_{3}$ decreases when the temperature is reduced from higher values to $31^{\circ} \mathrm{C}$, and it would be expected that $\Delta \eta$ would reflect this behaviour. We do see no sign of this. Undercooling cannot play a role, as the sample temperature for each measuring point is established independently. Therefore, without speculating on the behaviour of $\Delta \eta$ at positive $\alpha_{3}$, our data provide no evidence for $\alpha_{3}$ going to 0 as $T \downarrow 31^{\circ} \mathrm{C}$ for the frequencies used.

It was pointed out to us, that 8-CB has a well established inversion point for $\alpha_{3}$ and we hope to study this material soon.

Values for $\alpha_{4}$ are found immediately from $\eta_{\mathrm{A}}$. In table I we show our data for 7-CB and the literature data for 5-CB.

Table I. - Data in nematic state, $\alpha_{4}$ at $T_{\mathrm{NI}}-T=2 \mathrm{~K}, 1 \mathrm{PaS}=10$ Poise.

\begin{tabular}{|c|c|c|c|c|c|}
\hline Sample & $W_{\mathrm{s}} / k_{\mathrm{B}}$ & $W_{\mathrm{A}} / k_{\mathrm{B}}$ & $W_{\mathrm{BC}} / k_{\mathrm{B}}$ & $\alpha_{4}$ & $\alpha_{40}$ \\
\hline & $\mathrm{K}$ & $\mathrm{K}$ & $\mathrm{K}$ & $\mathrm{PaS}$ & $\mathrm{PaS}$ \\
\hline & $\times 10^{3}$ & $\times 10^{3}$ & $\times 10^{3}$ & $\times 10^{-3}$ & $\times 10^{-8}$ \\
\hline 5-CB & 3.3 & 4.3 & 3.3 & 53 & 4.5 \\
$7-\mathrm{CB}$ & 3.9 & 3.9 & 2.9 & 20 & 15 \\
\hline
\end{tabular}

The temperature dependence of the viscosities, both in the isotropic and the nematic state is of the form

$$
\eta(T)=\eta_{0} \mathrm{e}^{W / k_{B} T},
$$

where $W$ is an activation energy.

Removing the temperature dependence using equation (7) we find the underlying trend, with higher values for $\eta_{0}$ in 7-CB than 5-CB, as is reasonable to expect.

The activation energies for $\eta_{\mathrm{s}}, \eta_{\mathrm{A}}$ and $\eta_{\mathrm{B}, \mathrm{C}}$ are unremarkable. We include the information in table I.

Because of the experimental accuracy it is not meaningful to state the activation energy of $\Delta \eta$.

In the isotropic state the ultrasound viscosity $\eta_{\text {us }}$ is complex. We consider here only the real part, which is given by

$$
\eta_{\mathrm{us}}^{\prime}(\omega)=\eta_{\mathrm{s}}-\frac{2 \mu^{2}}{v} \frac{1}{1+\Gamma^{2} / \omega^{2}}
$$

where $\mu$ and $\nu$ are bulk viscosities and $\Gamma$ a relaxation time.

As we find no frequency dependence the second term in the denominator is apparently small and therefore :

$$
\eta_{\mathrm{s}}-\eta_{\mathrm{us}}^{\prime} \cong 2 \mu^{2} / v
$$

In table II we show the data for the isotropic state of 7-CB together with the literature data for 5-CB at $T-T_{\mathrm{c}}=2 \mathrm{~K}$. The smaller values for 7-CB are caused by the higher value for the transition temperature. Again the underlying trend after removal of the temperature dependence is higher for 7-CB, anologous to the behaviour in the nematic state.

More details of the present data, and comparable data on 5-CB and 6-CB will be published in a full paper. 
Table II. - Data in isotropic state, $\eta_{\mathrm{s}}$, $\eta_{\mathrm{us}}^{\prime}$ and $\eta_{\mathrm{s}}-\eta_{\mathrm{us}}^{\prime}$ at $T-T_{\mathrm{NI}}=2 \mathrm{~K}, 1 \mathrm{PaS}=10$ Poise.

\begin{tabular}{|c|c|c|c|c|c|c|c|c|}
\hline Sample & $W_{\mathrm{s}} / k_{\mathrm{B}}$ & $W_{\mathrm{us}} / k_{\mathrm{B}}$ & $\eta_{\mathrm{s}}$ & $\eta_{\mathrm{us}}$ & $\eta_{\mathrm{s}}-\eta_{\mathrm{us}}^{\prime}$ & $\eta_{\mathrm{s} 0}$ & $\eta_{\text {us }}^{\prime}$ & $\eta_{\mathrm{s} 0}-\eta_{\text {us }}^{\prime}$ \\
\hline & $\mathrm{K}$ & $\mathrm{K}$ & $\mathrm{PaS}$ & $\mathrm{PaS}$ & $\mathrm{PaS}$ & $\mathrm{PaS}$ & $\mathrm{PaS}$ & $\mathrm{PaS}$ \\
\hline & $\times 10^{3}$ & $\times 10^{3}$ & $\times 10^{-3}$ & $\times 10^{-3}$ & $\times 10^{-3}$ & $\times 10^{-8}$ & $\times 10^{-8}$ & $\times 10^{-8}$ \\
\hline 5-CB & 4.3 & 4.2 & 22 & 16 & 6 & $\begin{array}{l}2.6 \\
10\end{array}$ & $\begin{array}{l}1.9 \\
7.6\end{array}$ & $\begin{array}{l}0.7 \\
2.4\end{array}$ \\
\hline
\end{tabular}

Acknowledgments. - We acknowledge financial support and supply of sample materials from BDH Chemicals, Ltd., G. B., helpful discussions with Dr. B. Sturgeon and Dr. I. Sage of BDH Chemicals, Ltd., with Dr. P. Martinoty and Dr. Y. Thiriet of the Université Louis Pasteur, Strasbourg, and with Dr. M. G. Clark, RSRE, Great Malvern, G. B. SDH acknowledges the receipt of a CASE student grant from the SERC, Great Britain and BDH Chemicals, Ltd.

\section{References}

[1] Clark, M. G., Saunders, F. C., Shanks, I. A. and Leslie, F. M., Mol. Cryst. Liq. Cryst. 70 (1981) 195.

[2] Skarp, K., Lagerwall, S. T., Stebler, B. and McQueen, D., Phyš. Scripta 19 (1979) 339.

[3] Martinoty, P. and Candau, S., Mol. Cryst. Liq. Cryst. 14 (1971) 243.

[4] Chandrasekhar, S., Liquid Crystals (Cambridge Un. Press) 1977.

[5] Mason, W. P., Baker, W. O., McSkimmin, H. J. and Heiss, J. H., Phys. Rev. 75 (1949) 936.

[6] KIRY, F., Thesis, Strasbourg (1978).

[7] Kiry, F. and Martinoty, P., J. Physique 38 (1977) 153.

[8] Constant, J. and Raynes, E. P., Mol. Cryst. Liq. Cryst. 62 (1980) 115. 